\title{
Corruption and ISO 37001: A new instrument to prevent it in international entrepreneurship
}

\author{
Valerio Brescia \\ Department of Management, University of Turin, Italy \\ valerio.brescia@unito.it
}

\begin{abstract}
Corruption is a distorting factor in the market and has negative effects on both public and private administrations. It strongly affects international companies with high investments and high revenues, influencing also the work of managers and decision-makers. After a brief analysis of the context, the study proposes the analysis of a new risk assessment tool to prevent corruption. This is the ISO 37001: 2016, a new UNI standard that, according to our analysis, sees itself perfectly in a rational administration system and addresses all drivers that lead to corruption behaviors.
\end{abstract}

Keywords: anti-corruption; ISO 37001; corruption; risk assessment

\section{Introduction}

Corruption is a constant concern for countries facing and analyzing the causes of the economic crisis and a considerable amount of research has come to understand its economic effects. The World Bank defined corruption as "abuse of the public Duty to generate private profit" [1]. Transparency International provides a similar but more general definition of "abuse of entrusted power to generate private profit", which is not limited to the public sector as in the World Bank but extends it to the private one. Going to analyze the causes in literature related to corruption and the factors that influence, we can begin to have an overall consideration of the phenomenon. Bardhan [2] suggested that the effect of corruption on growth was negative, but based its conclusion on the historical analysis. The study that draws on its deductions on contemporary empirical experience is by Mentre Wei [3] who concluded that corruption had an adverse effect on growth by discouraging foreign direct investment and encouraging increased spending in government by distorting the composition of public spending. There are several pieces of evidence of how corruption has negative effects on the economic growth. From other macroeconomic studies, it turns out that the most corrupt society can allow for greater tax evasion, as corrupt officials seek more income through bribes; On the contrary, higher tax evasion can lead to corruption by offering more opportunities for bribes. Empirical evidence that controls the potential indigenousness of evasion and corruption shows that corruption is to a large extent leading to higher levels of evasion. "Tax evasion" is a related but very different concept, and refers to illegal and intentional actions taken by individuals by reducing their legal tax obligations. Despite all this work on corruption and tax evasion, there is very little work on their interrelation, especially as far as business is concerned. The existence of a theoretical analysis combining corruption

Article Info:

Received (May 12, 2017), Review Result (August 04, 2017), Accepted (October 22, 2017) 
and evasion does not focus on companies but on families [4]-[8]. Although corruption and tax evasion may exist separately, they can easily become embittered. Corruption allows tax evasion, making it easier for taxpayers to conceal their income, while tax evasion can contribute to corruption by creating additional opportunities for corruption. Some studies show that corruption is a driver for evasion. The presence of tax inspectors requesting bribes involves a reduction in reported tax sales between 4 and 10 percentage points. Moreover, higher bribes involve higher levels of evasion. These findings support the argument that tax compliance depends on the quality and honesty of tax authorities [9]. Some studies have highlighted how the corruption culture of a company, as well as the corruption average attitude of officials and executives of a company using their cultural information, falls on the corporate structure. The main finding of the study is that the culture of corporate corruption has a significant positive effect on corporate misconduct, such as earnings management, accounting fraud and opportunistic trading of insiders. The effects are also economically significant: an increase in standard deviation in a company's corruption culture is associated with an increase in the probability of bad business conduct by about 2-7\% [10]. According to the Global Corruption Report, the sector where corruption is most present in the health sector [11]. Corruption is responsible for the lack of improvement in the health of different populations [12]. Another area where the influence of corruption is evident in the military one, there is a correlation between growth in military spending and corruption. In this case, it is also shown that the relationship between economic growth and public expenditure is less than the expenditure itself, thus not empirically justifying the effect of corruption [13]. International entrepreneurship is growing and has many potentialities, although it grows at different speeds by sectors [14]. Given the characteristics of international entrepreneurship and the push of managers, it is clear that our industry-based analysis is based on complex business structures often present in multiple states [15], which need advanced risk assessment tools [16]-[19]. All studies and evidence lead to looking for a tool to be used to prevent corruption, thus avoiding market distortions. It is shown how the tool must be generalizable and applicable to both public and private sectors and must be able to engage and act on all drivers that can lead to corruption. The study intends to investigate the new corporate management and control system introduced by ISO 37001: 2016 and to analyze whether the volunteer tool can deal with expressive drivers that encourage corruption, subsequently highlighting the potential positive effects for the company after the introduction of the instrument. In almost all states with a developed economy, penalties have been introduced to prevent corruption as the only tool available to the government, but as we have seen in the literature, these are not sufficient if not helped also by efficient tools other than the legislative one. The tool is placed and integrates into theories related to rational administration [20], [22]-[26].

\subsection{Anti-corruption and reference background}

The spread of anti-corruption rules is becoming increasingly widespread with increased sanctions. We refer, for example, to:

- Foreign Corrupt Practice Act (FCPA) which applies in principle to America for offenses committed abroad, although the only link with the United States is that the operation goes through the United States.

- UK Bribery Act 2010 (UKBA) which stipulates that the British company or any person associated with the United Kingdom, even though birth, having a British passport or residence can be prosecuted for bribes that they pay anywhere in the world. 
The laws of the United Kingdom and of the United States are contributing to the development of international standards for the global fight against corruption. However, many other countries also have or are about to strengthen their anti-corruption legislation. In Table 1, the description of the elements of the two rules described previously useful to understand the need for a common tool; both rules derive from applying countries which employ and present a common-law system.

Table 1. Elements of British and US rules

\begin{tabular}{|c|c|}
\hline US FCPA 1977: Main elements & UK Bribery Act 2010: Main elements \\
\hline It bans corruption of foreign public officials (not the US) & It covers both public and private corruption \\
\hline $\begin{array}{l}\text { Corruption concept: Any action that can induce foreign officials } \\
\text { to help and/or obtain/maintain business illegally }\end{array}$ & $\begin{array}{l}\text { It strikes both who gives and who receives } \\
\text { bribes }\end{array}$ \\
\hline $\begin{array}{l}\text { Scope of application: US issues, US companies, Other people } \\
\text { who acted in support of illegal payments made in the US }\end{array}$ & $\begin{array}{l}\text { A specific ban on bribery of foreign public } \\
\text { officials }\end{array}$ \\
\hline $\begin{array}{l}\text { Books/Registers and Internal Controls: keeping the records and } \\
\text { internal control system to avoid the deliberate falsification of } \\
\text { books and/or accounting writings }\end{array}$ & $\begin{array}{l}\text { It accuses the Company incapable of } \\
\text { preventing the corruptive fact committed by } \\
\text { the associated person }\end{array}$ \\
\hline \multirow[t]{2}{*}{$\begin{array}{l}\text { Possible Defence for the Company: Shares that are legal } \\
\text { abroad, Bona Fide of Expense, Improper Facilitation/Payments }\end{array}$} & $\begin{array}{l}\text { Defence after demonstrating proper } \\
\text { procedures }\end{array}$ \\
\hline & $\begin{array}{l}10 \text { years of imprisonment (individual); } \\
\text { Unlimited fine (company) }\end{array}$ \\
\hline
\end{tabular}

However, we have been having for a long time a proliferation of international standards with the aim of avoiding corruption. One of the first in Singapore in 1960.

Table 2. Lists international regulatory developments

\begin{tabular}{|l|l|}
\hline \multicolumn{1}{|c|}{ Country } & \multicolumn{1}{c|}{ International regulations } \\
\hline SINGAPORE & Prevention of corruption law (1960) \\
\hline US & Foreign Corrupt Practices Act (FCPA) (1977) \\
\hline SAUDI ARABIA & $\begin{array}{l}\text { SAUDI ARABIA's Law for Combating Bribery } \\
\text { (Royal Decree N. M/36 1992) }\end{array}$ \\
\hline JAPAN & Unfair Competition Prevention Law (“UCPL” 1993) \\
\hline MALAYSIAN & Anti-corruption Act 575/1997 \\
\hline KOREAN & Anti-corruption Act n.6494/2001 \\
\hline G20 & AnticorruptionAction Plan (2010) \\
\hline UK & Bribery Act (2010) \\
\hline ISRAEL & New Legislation (2010) \\
\hline LUXEMBURG & $\begin{array}{c}\text { Amendments to Anti-Bribery legal Framework } \\
(2010)\end{array}$ \\
\hline
\end{tabular}




\begin{tabular}{|l|l|}
\hline IRELAND Act & Prevention of Corruption (Amendment) (2010) \\
\hline SLOVAK REPUBLIC & Amendment to criminal Code (2010) \\
\hline SPAIN & Amendment to Penal Code (2010) \\
\hline TURKEY & Series of Reforms (2010) \\
\hline CHINA & Amendments No. 8 to Article 164 (2011) \\
\hline UKRAINE & Anticorruption Law (2011) \\
\hline RUSSIA & Federal Law No. 97-FZ (2011) \\
\hline ITALY & Law n. 190/2012 (2012) \\
\hline MEXICO & Anticorruption in Public Contracts Law (2012) \\
\hline SOUTH AFRICA & The Companies Act Regulations (2012) \\
\hline ZAMBIA & AnticorruptionAct no 3 (2012) \\
\hline CANADA & CFPOA (2013) \\
\hline BRAZIL & Anti-Bribery Law (2013) \\
\hline INDIA & The Lokpal and LokayuktasAct (2014) \\
\hline
\end{tabular}

The States with legislative proposals are Australia and Indonesia. As we can see from the table from 2010 onwards, the sensitivity of different governments has increased. Almost all States with a developed economy at international trade and international level have legislation to prevent corruption. More than two-thirds of the 176 countries and territories in the Corruption Perceptions Index (2016) fall below half our 0 (highly corrupt) scale to 100 (very clean). The global average score is a page 43, which indicates endemic corruption in the public sector of a country. The most important countries (yellow on the map below) are still numerous, but the most worrying ones are the orange and red countries where citizens face daily the concrete impact of corruption (Figure 1). The lowest countries in our index are afflicted by unreliable and malfunctioning public institutions, such as police and judiciary. Even where anti-corruption laws have been published, they are often ignored. Higher countries tend to have higher levels of press freedom, access to information on public spending, higher standards of integrity for public officials and independent judiciary systems. But high-level countries cannot afford to be pleased. While the most obvious forms of corruption cannot affect the daily lives of citizens in all these places, the highest countries are not immune to closed-door operations, conflicts of interest, illicit finance and the application of the irregular law that could distort public policy and intensify corruption at home and abroad. 


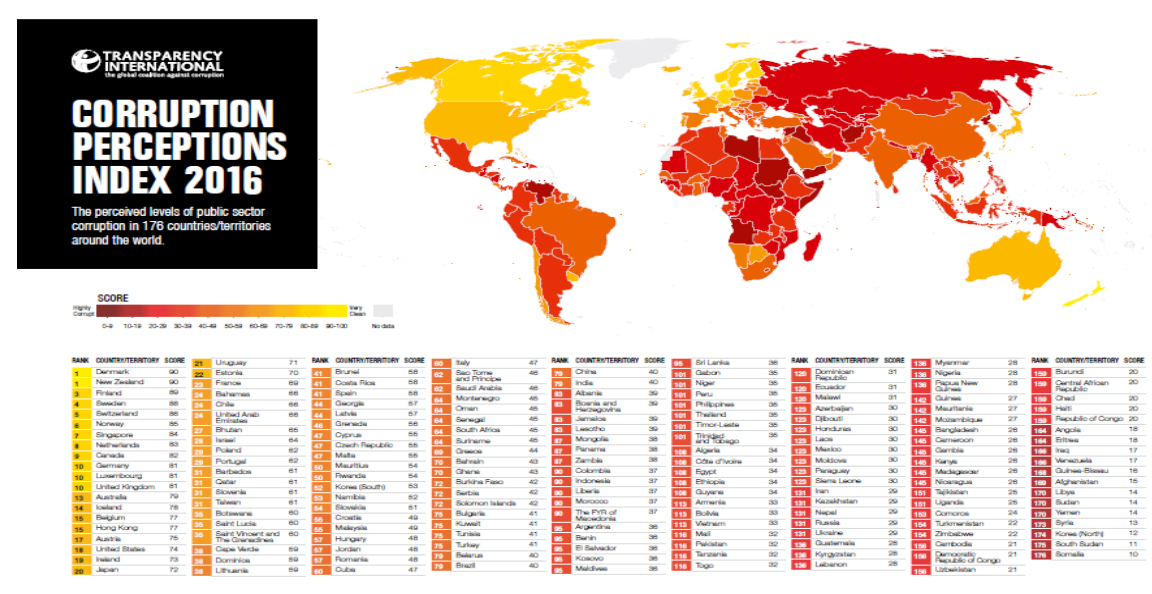

Figure 1. Corruption perceptions index 2016; source: transparency international

\section{Method}

Through a qualitative analysis of the composition of ISO 37001: 2016 regulation [27], we try to evaluate the presence of elements and phases of the regulation that can affect and control the identified corruption drivers. The analysis was conducted by highlighting both the discourse and comparison tables the main characteristics of the standard and of the instrument being analyzed.

\section{Discussion ISO 37001 and anti-corruption instruments}

The ISO 37001 standard, published on October 15, 2016, called "Anti-bribery management systems - Requirements with guidance for use" is a useful tool to tackle corruption. The responsible Technical Body is the Project Committee ISO / PC 278. As a rule adopted by the UNI, it is a tool that can be applied in all States and therefore it answers the need to be adopted with different laws. The regulation can be used alone or in conjunction with other management system regulations (e.g. ISO 9001, ISO 14001, ISO / IEC 27001, ISO 19600) and other management regulations (e.g. ISO 26000, ISO 31000). The regulation ISO 37001 that governs this tool applies only to corruption. It defines requirements and provides a guideline to help an organization: Prevent, detect, and respond to corruption, in addition, to Comply with anti-corruption legislation and other voluntary commitments applicable to its activities. The regulation is NOT specifically applicable to fraud, cartels and other competition violations, money laundering, and other corrupt practices. However, an organization may choose to extend the scope of its management system to include such activities. The requirements of ISO 37001 are general and are applicable to any organization (or part of the organization), regardless of the type, size, and nature of the activity. The terminology used in order to identify the responsibilities and actions to be taken has particular importance. In Table 3, the terminological description that then distinguishes the application of the instrument in its phases. 
Table 3. Main definitions of ISO 37001 Standard

\begin{tabular}{|c|l|}
\hline Terminology & \multicolumn{1}{|c|}{ Definition } \\
\hline Governing body & $\begin{array}{l}\text { Group or body that holds final responsibility and authority for the } \\
\text { activities, the administration and policies of the organization headed by } \\
\text { senior management and which controls the responsibilities of senior } \\
\text { management. }\end{array}$ \\
\hline Senior management & $\begin{array}{l}\text { Person or group of people who, at the highest level, direct and control } \\
\text { an organization }\end{array}$ \\
\hline Policy & $\begin{array}{l}\text { Orientations and addresses of an organization formally expressed by its } \\
\text { own senior management or by its governing body }\end{array}$ \\
\hline Organization & $\begin{array}{l}\text { Person or group of people having their own functions with } \\
\text { responsibility, authority and relationships to achieve their goals }\end{array}$ \\
\hline Involved part or & $\begin{array}{l}\text { Person or organization that can influence, be influenced, or perceive } \\
\text { itself as influenced by a decision or activity. }\end{array}$ \\
\hline Business partners & $\begin{array}{l}\text { The external part with which the organization has or plans to establish } \\
\text { any commercial relationship form. }\end{array}$ \\
\hline
\end{tabular}

In the instrument, corruption is defined as offering, promising and giving or accepting or soliciting an undue advantage of any kind (financial or non-financial), directly or indirectly, in violation of applicable law as a mechanism for inducing or rewarding a person so that it acts or avoids acting with consequences on the performance of their duties. This is the general definition of the regulation. It must be reviewed in the light of the definition of "corruption" in the national legal system to which it applies and of the definition given within the management system. The regulation applies to public, private, non-profit sectors and involves active corruption or passive corruption (Table 4).

Table 4. Definitions of active corruption and passive corruption

\begin{tabular}{|l|l|}
\hline \multicolumn{1}{|c|}{ Active corruption } & \multicolumn{1}{c|}{ Passive corruption } \\
\hline Corruption on behalf of the organization & Corruption of the organization \\
\hline $\begin{array}{l}\text { Corruption on behalf of personnel of the } \\
\text { organization acting on behalf of the organization or } \\
\text { for its benefit }\end{array}$ & $\begin{array}{l}\text { Corruption of the organization's personnel that acts } \\
\text { on behalf of the organization or for its benefit }\end{array}$ \\
\hline $\begin{array}{l}\text { Corruption on behalf of related individuals acting } \\
\text { on behalf of the organization or for its benefit }\end{array}$ & $\begin{array}{l}\text { Corruption of related individuals acting on behalf of } \\
\text { the organization or for its benefit }\end{array}$ \\
\hline Both direct and indirect (offered or accepted through/by a third party). \\
\hline
\end{tabular}

ISO 37001 establishes a bridge between two different cultures; that of management systems and that of organizational models and anti-corruption plans. A management system: "set of interrelated or interacting elements of an organization to establish policies and objectives and processes to achieve those goals" (from ISO 9001). An organization's compliance with ISO 37001's management system requirements does not mean that no case of corruption has occurred or may occur, but it means that the organization has done what 
reasonably (proportionately to the size and risks of the organization) possible to prevent corruption cases from occurring. The new High-Level Structure envisages alignment with other rules on management systems, identical titles, and key texts, basic vocabulary. Deming's cycle and rational administration integrate into the management of actions and administrative facts within the structure in order to develop a total quality system. ISO 37001 provides the following steps:

- Plan: Organization, roles and responsibilities (e.g. delegated decision making), internal and external context analysis, Anti Bribery Policy, Bribery risk assessment, definition of the Action Plan to introduce (cd. Action Plan), definition of supporting actions (resources such as bonuses or disciplinary systems, skills that the components of the structure must possess, information and training, archiving systems).

- Do: Action Plan Implementation, Due Diligence (e.g. Third Party, M \& A), Financial and nonfinancial controls, Gifts, hospitality, donations and similar benefits, Whistleblowing, Investigation.

- Check: monitoring and measurement, internal audit, review

- Act: continuous improvement

This risk assessment tool sees as a starting point the analysis of the organization's context as a start to assess the risks. The internal and external factors that are relevant to the organization (statutory and / or contractual / professional obligations, the structure and level of decision-making powers, the size and places where it operates, the controlled entities and / or that exert control over the organization, relations with public officials, business partners, etc.). It is necessary to identify the involved parts (public and private) whose expectations are to be taken into account. The scope of the system needs to be determined in terms of external and internal factors, involved parts' expectations, assessment of the risk of corruption. The organizational context needs to be analyzed day by day as it is necessary to identify and evaluate periodically (e.g. organizational changes and/or market/business) the risks that can be expected and the existing controls, though:

- Definition of evaluation criteria (e.g. low/medium/high) taking into account factors such as the nature of the risk, the probability, and the impact.

- Analysis of the organization's size/structure (e.g. concentration of management controls and/or decentralization)

- Analysis of the sectors and territories in which it operates (e.g. corruption indexes)

- Examining affiliated business entities (e.g. suppliers and/or agents)

- Examining the nature and frequency of interactions with national or foreign public officials

- Assessing the degree of influence and control on the above elements

It is essential that the risk assessment should be available in the form of documented information. For ISO 37001: 2016, risk assessment is a complex process that considers different factors, such as organizational size and organization (e.g. branches abroad), place and sectors in which the organization operates, activities and processes of the organization (small and medium-sized enterprises, multinationals, local government, public companies), business associates, public relations, breach of rules and regulations. The main phases of the risk management process are:

1. Context analysis: external context (characteristics of the external environment, e.g. cultural, criminological, social and economic variables of the territory, which may favour the occurrence of corrupt phenomena within the Entity); internal context governing bodies, organizational structure, roles and responsibilities; policies, goals, and strategies; resources, knowledge, systems and technologies; 
quality and quantity of personnel; organizational culture, with particular reference to the culture of ethics; information systems and flows, decision making (both formal and informal); internal and external relations.

2. Risk assessment: risk identification; risk analysis; risk weighting. After identifying the areas at risk, by means of interviews, the risk profile should be assessed in a concrete way in order to avoid identifying prevention measures that are too general and/or impracticable.

3. Identification of measures; programming of the measures. This phase aims at identifying the remedial measures and the most appropriate ways of preventing risks, based on the priorities emerging when assessing risky events and in particular adequately designed sustainable and verifiable measures.

It is proposed the analysis of an organization's business model with the identification of the organizational structure, roles and people in key positions (Key Officer) in Figure 2. The analysis starts from the value chain, considers processes of business and support processes in order to identify the areas of risk.

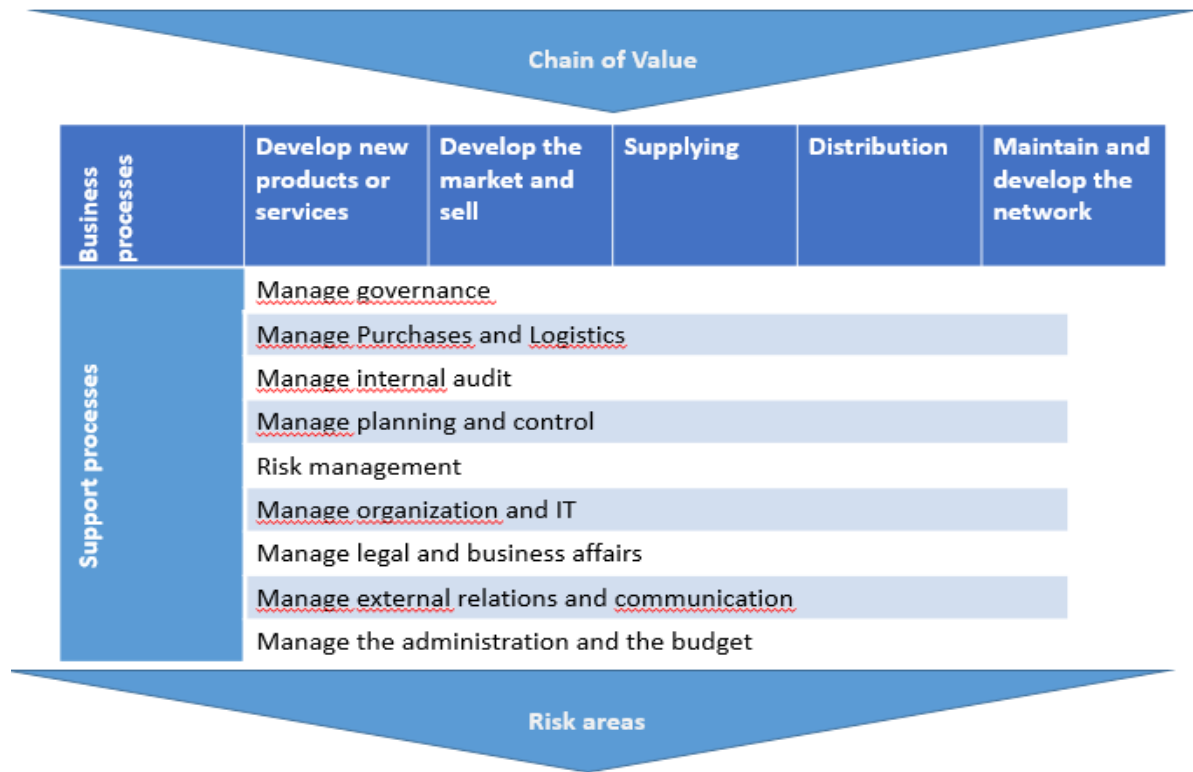

Figure 2. Analysis of the organizational model

The main areas at risk of active corruption are identified in the private sector in relationships with third parts (JV consultants, relations with public officials and/or loans to associations and foundations, financial flows, expeditions, personnel selection and management, trade and discount policy, donations and sponsorships to events. The main areas of passive corruption in the public and private sectors are: issuance of authorizations and/or permissions, issuance of certifications as independent third parts, implementation of thirdparty inspections, purchases and/or contracts, selection and management of personnel, provision of funds or contributions to third parties, donations, gifts and sponsorships to events.

To identify the risk, you have to consider the processes and understand how (through which behaviors) processes could be manipulated/altered to encourage corruption. This manipulation/alteration translates into an action on one or more elements of the internal control system. It is, therefore, possible to identify some types of risk behaviors that need to 
be evaluated. After evaluating the pertinent corruption risks, the organization can determine the type and level of controls for corruption's prevention applied to each category of risk and it can assess whether the controls in place are adequate. Otherwise, controls may be duly improved or the organization may change the nature of the transaction, project, activity or relationship so that the nature and extent of the risk of corruption are reduced. The assessment of corruption risk is not intended as an extensive and overly complex exercise and the results of the assessment do not need necessarily to prove to be correct (for example, a transaction assessed as a risk of low corruption may reveal the existence of acts of corruption). A strong leadership (formed by the Governing Body or the High Authority) is required to approve the policy of preventing corruption, make policy and objectives compatible with the strategic direction, ensure the effectiveness of the system by guaranteeing the allocation of adequate resources, supervise the implementation of the System, its integration into business processes and the involvement of people which must be assured by the Senior Management, promote reporting procedures and avoid retaliation. An "Anti-Corruption Compliance Function" is required with guidance tasks, system explanation, and reporting of results to the Governing Body or Senior Management. The Governing Body must approve/review an Anti-Corruption Policy that Forbids corruption (active and/or passive) and requires compliance with applicable laws in Italy and/or abroad, in accordance with the mission of the organization, provides a framework reference to achieve goals (e.g. integrated with other forms of corruption's prevention), encourages reports of suspected breaches, in good faith, explains the authority, the independence of the Anti-Corruption Compliance Function and its lines of reporting upwards. The policy must be available as documented information, communicated in the appropriate languages both internally and externally and bind in the relationships with the stakeholders in the appropriate ways. ISO 37001: 2016 identifies 3 responsible individuals: executive body, senior management, and anti-corruption compliance function, and is distinguished between a private company, public company, and public administration. Managers at every level must be responsible to request that the requirements of the corruption management system are applied and observed within their department or function table 5.

Table 5. Identification of the 3 responsible individuals according to ISO 37001 : 2016

\begin{tabular}{|c|c|c|c|}
\hline ISO 37001 & Private society & Public society & $\begin{array}{c}\text { Public } \\
\text { administration }\end{array}$ \\
\hline Governing body & $\begin{array}{c}\text { Board of Directors / } \\
\text { Supervisory Board }\end{array}$ & Board of Directors & Council/Mayor \\
\hline High supervision & $\begin{array}{c}\text { Managing Director / } \\
\text { General Direction }\end{array}$ & $\begin{array}{c}\text { Managing Director / } \\
\text { General Direction }\end{array}$ & General Secretary \\
\hline Anti-corruption & Compliance/Internal & Compliance/Internal \\
compliance function & Audit & Audit & Internal Audit Office \\
\hline
\end{tabular}

The High Supervision must assign to the Anti-Corruption Compliance Function the responsibility and authority to supervise the design and implementation of anti-corruption management system, provide advice and guidance to personnel about the anti-corruption management system and corruption-related issues, ensure the compliance of the anticorruption management system with the requirements of ISO 37001, draft the performance report of the Anti-Corruption Management System to the Governing Body (if available), to 
the High Supervision and / or other functions. Depending on the complexity of the organization, the function can be covered by a single person or by a group possessing status, competence, authority, and independence. The function can be entrusted entirely or partially to external subjects. However, they must answer a competent manager of the organization.

Considering the elements of the context, the stakeholders' expectations, and the risk analysis, the regulation requires planning actions to manage the risks and opportunities for improvement. The goals must be established for each relevant function and level, in line with anti-corruption policy, they must be measurable, monitorable, communicable and up-to-date. Planning must define who does what, how and when, as well as the results which will be evaluated and who will apply penalties. It is important at this stage that the criterion of reasonableness and proportionality, that is prevention and control measures should not be so burdensome to prevent activity or read as to prevent activity. In addition to the "Due Diligence" and "Reporting and Investigation Management" controls, other preventive measures have to be identified. Based on international best practices, these measures could be inspired by the following internal control standards:

1. Segregation of tasks: the protocol is based on the separation of tasks between those who authorize, execute and control.

2. Procedures: the protocol is based on the existence of business rules and/or formal procedures that are appropriate to provide principles of conduct, operating procedures to conduct sensitive activities, and how to store relevant documentation.

3. Authorization and signature powers: the protocol is based on the principle that the powers of authorizing and signing must be: (i) consistent with the assigned organizational and management responsibilities, providing, where requested, an indication of the approval thresholds; ii) clearly defined and known within the Company.

4. Traceability: the protocol is based on the principle that: (i) any activity relating to sensitive activity is, where possible, adequately recorded; (ii) the decision-making, authorization and conduct of the sensitive activity can be verified ex-post, also by means of appropriate documentary media; (iii) in any case, the possibility of deleting or destroying the registrations shall be governed in detail.

There must be adequate resources to achieve the desired goals such as staffing requirements, non-discriminatory personnel management procedures that highlight those exposed to risk situations, disciplinary and / or rewarding system, training actions for the most exposed personnel for "Business Associate" CDs, a well-defined internal and external communication process, pieces of information that document the policy, procedures and controls of the management system, the results of the risk analysis, the training provided, the actions taken, the results of the monitoring, the "incidents" related to suspected or actual corruption cases. Due diligence third parties are all staff who have third-party relationships and who must check the selection process, the adequacy of the economic commitment and professionalism/integrity, the receipt of all the approvals required for signing the agreement and performance certification, acceptance and adherence to the anti-corruption management system. The organization must evaluate the nature and extent of the risk of corruption in relation to transactions, projects, activities, business partners and specific staff members that fall into predefined categories as at greater risk. Based on the outcome of the risk assessment, the organization must implement procedures that require that all other organizations which it controls and the application of the anti-corruption management system, or the implementation of their controls for the prevention of corruption. In relation to business partners, based on the outcome of the risk assessment and/or due diligence, the organization must determine whether the business partner is implementing anti-corruption controls that handle the relative 
risks of corruption; where a business associate does not implement checks to prevent corruption or it is not possible to verify whether he/she carries them out, he/she must require to do so contractually and in negative case consider this element as a risk factor in the risk assessment.

Reporters who relate periodically to the Anti-Corruption Compliance Function should be identified to update both the performance and adequacy of the entire organization's system and the monitoring activities performed by the Anti-Corruption Compliance Function, executives and other staff involved in the risk areas, Referents (Apical or Director). To this end, it is necessary to define and communicate formally to all involved individuals the contents, frequency, and mode of transmission. For example, information flows may include: state-of-the-art workflows and / or change risk areas / controls from Referents, internal / external factor exchange and system review, Key Risk Indicators and / or Red Flags (e.g. desert races, single and / or emergency assignments), summary reports prepared by Surveillance Bodies or other Internal Control Bodies (e.g. auditors), other information such as disciplinary proceedings. Operationally, procedures are required to regulate the receipt/promise of various forms of gratuities and / or other "benefits" deemed unlawful with special attention to "suspect" cases, application of procedures to encourage and use the reports of suspected anonymous ("whistle blowing"), protecting confidentiality and staff reporting, applying procedures to independently investigate suspected or actual corruption cases. The organization at the evaluation stage must determine what is required to monitor and measure, who is responsible for monitoring, monitoring methods, measurement, analysis and evaluation, as applicable, to ensure valid results when monitoring and measurement are to be performed, when the results of monitoring and measurement must be analysed and evaluated, to whom and how such information should be reported. It is also required to carry out internal audits, a review of the High Supervision (and the Governing Body, if any), a continuous review by the Anti-Corruption Department, which reports back to the High Supervision and to the Governing Body, where existing. Auditing (or inspection test) means an independent auditing activity carried out internally by the Entity to ascertain, by selecting a sample of transactions, the compliance of the activities carried out by staff and collaborators with respect to what is prescribed. Auto Evaluation is a self-assessment questionnaire filled out by staff involved in risk areas to identify any changes in risk and/or administrative areas, level of perception of corruption/value of integrity and level of knowledge of prevention measures, anomalies, and criticalities in process management. The High Supervision must, at scheduled intervals, review the management system to ensure its continuing suitability, adequacy, and effectiveness. The High Supervision review must include consideration of the status of actions resulting from previous management reviews, changes to external and internal aspects that are relevant to the system, system performance information, including noncompliance trends and corrective actions, monitoring and measurement results, audit results, corruption reports, investigations, the nature and extent of the corruption risks faced by the organization, the effectiveness of the actions taken to address the risks of corruption, opportunities for continuous improvement. When a nonconformity occurs, the organization must react promptly to non-compliance and, as far as it is possible to take action to keep it under control and correct it, to address its consequences, to assess the need for action to eliminate the cause or causes of non-compliance so that it does not repeat or do not occur elsewhere by reviewing non-conformities, determining the causes of noncompliance, determining whether or not there may be similar nonconformities, as well as carrying out any necessary action and reviewing the effectiveness of any corrective action taken. The 
organization must continuously improve the sustainability, adequacy, and effectiveness of the system.

All of the most relevant analyzed points in the ISO 37001: 2016 standard allow to focus on the different drivers and the various factors that affect both the organization's and managers 'or decision-makers' corruption behavior. In addition, analysis of functions and processes and governance control, including the training and characteristics that individuals must possess, allows immediate intervention in companies even in complex structures and in different markets and international regulations.

\section{Conclusion}

ISO 37001 can be an innovative tool for international companies that carry out their business in a global market and that, because of their complexity, systematize systems to prevent corruption and related sanctions, thus leading to an economic and competitive advantage for the same company. The regulation applies both to groups and public companies as well as to private groups and companies that can be implemented indifferently from the type of reference needs and markets, and it affects several drivers related to the phenomenon of corruption. The management benefit is identifiable in adopting a unique language and international standards for the prevention of corruption (in their case it is very useful, given their international dimension to FCPA / UKBA). The system-related advantage involves a single language that is based on the SL platform, the same used for other management systems (e.g. ISO 9001) and therefore with the implementation of ISO 37001 several elements (e.g. policy, review, etc.) can be integrated without weighing up the organizational structure. However, there are also significant benefits to governance. In particular, the study has strengthened the existing control protocols to prevent active corruption towards public administration / private citizens and/or passive corruption within public administration (strengthening first / second level controls) and whistleblowing system. Strengthening control protocols on "Third Parties" (e.g. agents, distributors, freight forwarders, etc.) and therefore greater integration between the Internal Control Model and the Anti-Corruption Global Policies (e.g. FCPA / UKBA) in addition to the possibility according to the risk profile of the "Third parties" to request them also the ISO 37001 certification (e.g. countries with greater risk) in a coordinated manner with any indication of the Global Policy Parent Company. With the implementation of the 37001 system, there is a strengthening of third level controls and/or the Supervisory Authority, which in this way will focus more on other areas at risk of the whole system less guarded (e.g. laundering and/or anti-laundering, organized crime, etc.), leveraging information flows. At the level, the instrument allows to increase and strengthen evidence in case of "legal defense". Always at the economic level, it is possible to take advantage of the adoption of ISO 37001 Management Systems as a pricing requirement to have the legality rating in the control of each State and the possibility of being facilitated in brand reputation terms and particularly for international customer qualification systems with the possibility of reducing their contract audits. Being a voluntary tool cannot be defined as resolved in the absolute terms of the corruption phenomenon in public and private companies. The fact that a third party performs the audit increases the autonomy and truthfulness of what has been stated [21].

\section{Limitations:}

The tool was recently introduced by the standard, so there are not enough cases to analyze the actual relapse between companies and groups that adopt it and those who have not adopted it. Major evidence will take several years. 


\section{References}

[1] B. Mundial, "Helping countries combat corruption: the role of the World Bank, PREM, September (1997).

[2] P. Bardhan, "Corruption and development: a review of issues", Journal of Economic Literature, Vol. 35, No. 3, pp. 1320-1346, (1997).

[3] S.J. Wei, "Corruption in economic development: Beneficial grease, a minor annoyance, or major obstacle?", (1999).

[4] P. Chander, and L. Wilde, "Corruption in tax administration", Journal of Public Economics, Vol. 49, No. 3, pp. 333-349, (1992).

[5] T. Besley, and J. McLaren, "Taxes and bribery: the role of wage incentives", The Economic Journal, Vol. 103, No. 416, pp. 119-141, (1993).

[6] J. Hindriks, M. Keen, and A. Muthoo, "Corruption, extortion, and evasion", Journal of Public Economics, Vol. 74, No. 3, pp. 395-430, (1999).

[7] A. Acconcia, M. D'Amato, and R. Martina, "Corruption and tax evasion with competitive bribes", Centre for Studies in Economics and Finance Working Paper No. 112, (2003).

[8] S.H. Akdede, "Corruption and tax evasion”, Doğuş Üniversitesi Dergisi, Vol. 7, No. 2, pp. 141-149, (2011).

[9] J. Alm, J. Martinez-Vazquez, and C. McClellan, "Corruption and firm tax evasion", Journal of Economic Behavior \& Organization, Vol. 124, pp. 146-163, (2016).

[10] X. Liu, "Corruption culture and corporate misconduct", Journal of Financial Economics, Vol. 122, No. 2, pp. 307-327, (2016).

[11] B.S. Aregbeshola, "Institutional corruption, health-sector reforms, and health status in Nigeria", The Lancet, Vol. 388, No. 10046, pp. 757, (2016).

[12] M. Lewis, "Governance and corruption in public health care systems", (2006).

[13] G. D'Agostino, J.P. Dunne, and L. Pieroni, “Government spending, corruption and economic growth", World Development, Vol. 84, pp. 190-205, (2016).

[14] B.M. Oviatt, and P.P. McDougall, "Defining international entrepreneurship and modeling the speed of internationalization", Entrepreneurship Theory and Practice, Vol. 29, No. 5, pp. 537-554, (2005).

[15] S.A. Zahra, and G. George, "International entrepreneurship: The current status of the field and future research agenda”, Strategic Entrepreneurship: Creating a New Mindset, pp. 255-288, (2002).

[16] P.W. Liesch, L.S. Welch, and P.J. Buckley, "Risk and uncertainty in internationalization and international entrepreneurship studies”, Management International Review, Vol. 51, No. 6, pp. 851-873, (2011).

[17] T.C. Sebora, and T. Theerapatvong, "Corporate entrepreneurship: A test of external and internal influences on managers' idea generation, risk-taking, and proactiveness”, International Entrepreneurship and Management Journal, Vol. 6, No. 3, pp. 331-350, (2010).

[18] C. Brush, "International entrepreneurship: The effect of firm age on motives for internationalization", Routledge, Vol. 5, (2012).

[19] P. Dimitratos, I. Voudouris, E. Plakoyiannaki, and G. Nakos, "International entrepreneurial culture-Toward a comprehensive opportunity-based operationalization of international entrepreneurship", International Business Review, Vol. 21, No. 4, pp. 708-721, (2012).

[20] P. Biancone, S. Secinaro, and V. Brescia, "Popular report and Consolidated Financial Statements in public utilities. Different tools to inform the citizens, a long journey of the transparency", International Journal of Business and Social Science, Vol. 7, No. 1, (2016).

[21] C. Rainero, and V. Brescia, "Corporate Social Responsibility» and «Social Reporting»: The Model of Innovation «Piedmont Method”, International Journal Series in Multidisciplinary Research (IJSMR), Vol. 2, No. 3, pp. 18-40, (2016).

[22] L. Puddu, "Il processo di accumulazione del capitale, l'analisi funzionale del management, l'amministrazione razionale e la classificazione delle aziende: razionalità della rilevanza e valori etici”, Egea, Milano, (2010). 
[23] L. Puddu, P.P. Biancone, S. Secinaro, and M.C. Vietti, "Il bilancio consolidato delle aziende pubbliche locali: Ipsas e Principi contabili nazionali a confront, (2016).

[24] C. Lusa, L. Puddu, C. Rainero, and L. Scagliola, "La certificazione dei processi amministrativi nelle aziende sanitarie", G Giappichelli Editore, Vol. 6, (2016).

[25] K. Praveen Kumar, "Enhanced Methodology for Relation Descriptor Extraction", International Journal of ITbased Management for Smart Business (IJTTMSB), GVSchoolPub, Vol. 1, No. 1, December (2014).

[26] M.J. Kim and E.H. Kim, "A Study on Perceived Performance Risk and Product Attitude in accordance with Price Discount and Product Types of Korea and Thailand Consumers", International Journal of IT-based Management for Smart Business (IJITMSB), GVSchoolPub, Vol. 3, No. 1, pp. 29-36, December (2016).

[27] UNI EN ISO 37001:2016 20 December (2016).



\begin{abstract}
Author

\section{Valerio Brescia}

$\mathrm{Ph} . \mathrm{D}$. Candidate in Business and Management at the University of Turin, Italy with the research topic in the Consolidated Financial Statements of the municipality, accounting standards, and Popular Report. He holds a master's degree in Economic Sciences Company - firms Administration and Control at the School of Management and Economics in Turin with full marks and has a Master in Management of local health facilities and hospitals from the University of Turin.
\end{abstract}

